\title{
APERFEIÇOAMENTO DA GESTÃO ORGANIZACIONAL POR MEIO DA ABORDAGEM MULTICRITÉRIO DE APOIO À DECISÃO
}

\section{ORGANIZATIONAL MANAGEMENT IMPROVEMENT BY THE USE OF MULTICRITERIA DECISION AID APPROACH}

\author{
Edilson Giffhorn ${ }^{1}$; Leonardo Ensslin ${ }^{2}$; Sandra Rolim Ensslin ${ }^{3}$; William Barbosa Vianna ${ }^{4}$ \\ ${ }^{1}$ Universidade Federal de Santa Catarina - UFSC - Florianópolis - Brasil \\ edilson.giffhorn@gmail.com.br \\ ${ }^{2}$ Universidade Federal de Santa Catarina - UFSC - Florianópolis - Brasil \\ ensslin@deps.ufsc.br \\ ${ }^{3}$ Universidade Federal de Santa Catarina - UFSC - Florianópolis - Brasil \\ sensslin@gmail.com \\ ${ }^{4}$ Universidade Federal de Santa Catarina - UFSC - Florianópolis - Brasil \\ wpwilliam@hotmail.com
}

\begin{abstract}
Resumo
O acelerado processo de crescimento brasileiro no setor de telecomunicações iniciado a partir da privatização do sistema Telebrás desencadeou a adoção da Terceirização nos projetos de expansão $e$ implantação dos equipamentos de voz e dados pelas empresas operadoras do sistema. No entanto, a escassez ou mesmo ausência de modelos de avaliação de desempenho de empresa terceirizadas, que evidenciem critérios relevantes pelos decisores, favorecem a situação em que as decisões quanto à contratação das mesmas sejam predominantemente baseadas em critérios intuitivos, favorecendo a possibilidade da ocorrência de inúmeros problemas tais como retrabalho, custos adicionais e, sobretudo, desgaste na imagem das operadoras perante seus clientes. $O$ presente artigo utiliza a Metodologia Multicritério em Apoio à Decisão - Construtivista (MCDA-C) para desenvolver um modelo de avaliação do desempenho de empresas terceirizadas que atuam na área de telecomunicações.
\end{abstract}

Palavras-chave: avaliação de desempenho, gestão organizacional, gestão de projetos, multicritério de apoio à decisão.

\section{Introdução}

O atual estágio e ritmo de crescimento econômico do Brasil vêm exigindo um aprimoramento cada vez maior da infra-estrutura do país. Um dos setores mais diretamente afetados por este desafio de crescimento é o das telecomunicações. Uma vez que para a configuração de uma sociedade baseada no conhecimento se utiliza cada vez mais de tecnologias de informação e comunicação como um dos principais traços característicos do desenvolvimento, seja em nível local 
ou global.

A rapidez das mudanças e exigências no mercado consumidor de telecomunicações foi marcada inicialmente pela quebra do monopólio estatal em 1998. A partir deste momento, os novos desafios que se impuseram às empresas operadoras do sistema, tais como o crescente aumento na demanda por serviços de voz e dados, resultaram na necessidade da terceirização de parte dos serviços, o que permitiu a concentração de forças nas competências essenciais.

No entanto, a inexistência de modelos que explicitem os critério utilizados para homologar as empresas terceirizadas, com base em processos sistêmicos de avaliação de desempenho, expõe as operadoras à ocorrência de muitos problemas geradores de prejuízos à qualidade, retrabalhos, custos adicionais e, sobretudo, prejuízo para a imagem perante os clientes.

No caso em estudo, o processo de aceitação de empresas terceirizadas para trabalhar em comunicação de dados e voz, não evidenciava os quesitos que o decisor julgava relevantes, no entanto, uma vez que a pressão por compressão dos cronogramas para atingir as metas dos resultados levava o mesmo a decidir sobre o aceite das contratadas de forma predominantemente intuitiva.

O presente artigo descreve um estudo de caso no qual foi desenvolvido um modelo personalizado para o Gestor de Projetos de uma grande empresa de telecomunicação, somente no primeiro semestre de 2007 foram efetuadas mais de 823 obras, com atuação no sul do Brasil. Com a construção de um modelo de avaliação de desempenho baseado nos critérios julgados importantes pelos decisor, o mesmo passou a dispor de um instrumento de apoio à decisão ao homologar as empresas.

No desenvolvimento de tal modelo se utilizou a Metodologia Multicritério de Apoio à Decisão - Construtivista (MCDA-C). A metodologia MCDA-C permitiu identificar os aspectos críticos para a realização dos trabalhos terceirizados em comunicação de dados, bem como possibilitou o desenvolvimento de um modelo adequado às necessidades do decisor, modelo este legitimado pelo mesmo ao longo do processo.

A MCDA-C foi escolhida para o desenvolvimento do modelo tendo em vista a complexidade da situação, o fato de haverem múltiplos objetivos conflitantes e principalmente porque os objetivos necessitavam ser explicitados, organizados e mensurados (ENSSLIN et al, 2000). Com a construção do modelo de avaliação, a organização estudada e o decisor passaram a dispor de um instrumento de gestão do desempenho das terceirizadas e de apoio à decisão para homologá-las.

A MCDA-C, segundo Ensslin e Vianna (2007), utiliza de forma particular o método de pesquisa quali-quantitativo, e para isto, os instrumentos de coleta de dados empregados foram a Entrevista Aberta, o Questionário Aberto e a Pesquisa Bibliográfica, como estratégia de pesquisa é 
Pesquisa Aplicada e Obstrusiva na forma de estudo de caso.

Inserida no contexto exposto, pergunta-se: é possível, no caso de escolha e monitoramento de empresas terceirizadas, identificar, organizar e medir a performance dos aspectos julgados relevantes pelo Gestor de Projetos de uma empresa?

\section{Terceirização e Avaliação de Desempenho}

Para ganhar velocidade, flexibilidade e especialização em meio à crescente dinamicidade do ambiente competitivo, as organizações estão promovendo terceirizações de suas atividades suporte, o que permitiu a concentração de forças nas competências essenciais. No entanto, ao assim proceder, as organizações passaram a ter uma estreita relação de dependência com o desempenho das empresas terceirizadas, pois essas passam a exercer um papel fundamental nos resultados da contratante em relação à qualidade e imagem perante os clientes.

A Terceirização está associada à Especialização Flexível, que significa empresas especializadas atuarem com flexibilidade e velocidade suficientes para atender às constantes alterações nas demandas dos clientes. Sua principal característica reside em ser um processo que ocorre quando determinada atividade deixa de ser realizada pelos colaboradores de uma empresa e é transferida a outra, chamada Terceira. Ao assim proceder, a empresa contratante pode focar esforços em sua atividade fim (RAMOS, 2002).

A transferência de atividades para terceiros já é praticada pelas organizações há muito tempo. Desde o século XVIII na Inglaterra, atividades muito especializadas ou que não interessavam economicamente eram transferidas a pessoas ou empresas mais capacitadas, externas à organização (BERGAMASCHI, 2004).

O conceito moderno de terceirização como transferência do sistema produtivo e da flexibilização nas relações trabalhistas teve início com a Segunda Guerra Mundial, devido à necessidade de rápido incremento na produção de armamentos. O conceito da terceirização evoluiu e deslocou o foco da redução de custos para a melhoria do desempenho e busca da inovação.

A burocratização e a verticalização tornam as organizações lentas na tomada de decisões, o que reduz a agilidade para se adaptar ao mercado. A ausência de processos participativos devido à centralização do poder resulta em problemas no desempenho das atividades e das relações de trabalho, culminando no seu engessamento e no aumento da possibilidade de se ficar em uma desvantagem competitiva (RAMOS, 2002).

No Brasil, a adoção da Terceirização foi inicialmente muito gradual, mas ganhou força a partir do início da década de 1990 com o fim das leis de reserva de mercado, do aumento dos custos fixos, da carga tributária e do número de insumos necessários para executar as atividades suporte. 
No ramo de telecomunicações, a terceirização foi definitivamente incorporada a uma série de atividades com a privatização das empresas pertencentes ao grupo Telebrás no final da década de 1990.

Para ser bem sucedida, a terceirização deve instaurar um processo de avaliação do desempenho das empresas terceirizadas, que seja adaptado à realidade da empresa cliente. Dentre as diferentes formas de realizar a avaliação de desempenho, a que melhor incorpora explicitamente o sistema de valores dos decisores e que tem o foco na geração de entendimento do contexto decisional aos stakeholders é a Metodologia Multicritério de Apoio à Decisão - Construtivista.

\section{Metodologia Multicritério de Apoio à Decisão - Construtivista (MCDA-C)}

A Pesquisa Operacional expressa pelas abordagens Multicritérios de Apoio à Decisão (MCDA) originaram-se na década de 1970 na Europa, e posteriormente nos Estados Unidos, possuem diversificadas formas de desenvolver modelos para resolução de problemas em Apoio à Decisão. O agrupamento dessas abordagens por convicções fundamentais de comunidades científicas tem originado diferentes escolas de pensamento, entre elas a Multicritério em Apoio à Decisão - Construtivista.

Essa escola utiliza-se da sigla MCDA-C, a qual incorpora e propõe explicitamente o uso do adjetivo ‘Construtivista' para caracterizar a sua prática científica, cujo principal diferencial está no desenvolvimento de modelos personalizados que levam em conta fortemente os objetivos e valores dos decisores, possibilitando ao mesmo participar ativamente em todas as fases de desenvolvimento do modelo, legitimando-o constantemente.

Segundo Roy e Vanderpootem (1996), o Apoio à Decisão parte do pressuposto de que os processos decisórios são complexos e tem em conta os limites da objetividade, tornando-se, assim, de fundamental importância a construção de modelos que contemplem a subjetividade dos atores envolvidos com a solução de problemas e/ou com o ato de decidir. Os processos decisórios, nesta visão, passam a ser personalizados.

A Figura 1 apresenta as fases constituintes do processo de construção do modelo de avaliação de desempenho segundo a metodologia MCDA-C.

A Estruturação se constitui no fator mais crítico ao sucesso, pois visa o entendimento do problema e de todo o contexto onde o mesmo está inserido (ENSSLIN et al, 2005). Essa fase é dividida em três etapas. Na segunda etapa são identificados e construídos os Pontos de Vista Fundamentais (PVFs) e a terceira etapa é da construção dos descritores. Nesta etapa são construídas as escalas ordinais que serão utilizadas para mensurar localmente e globalmente o contexto. 


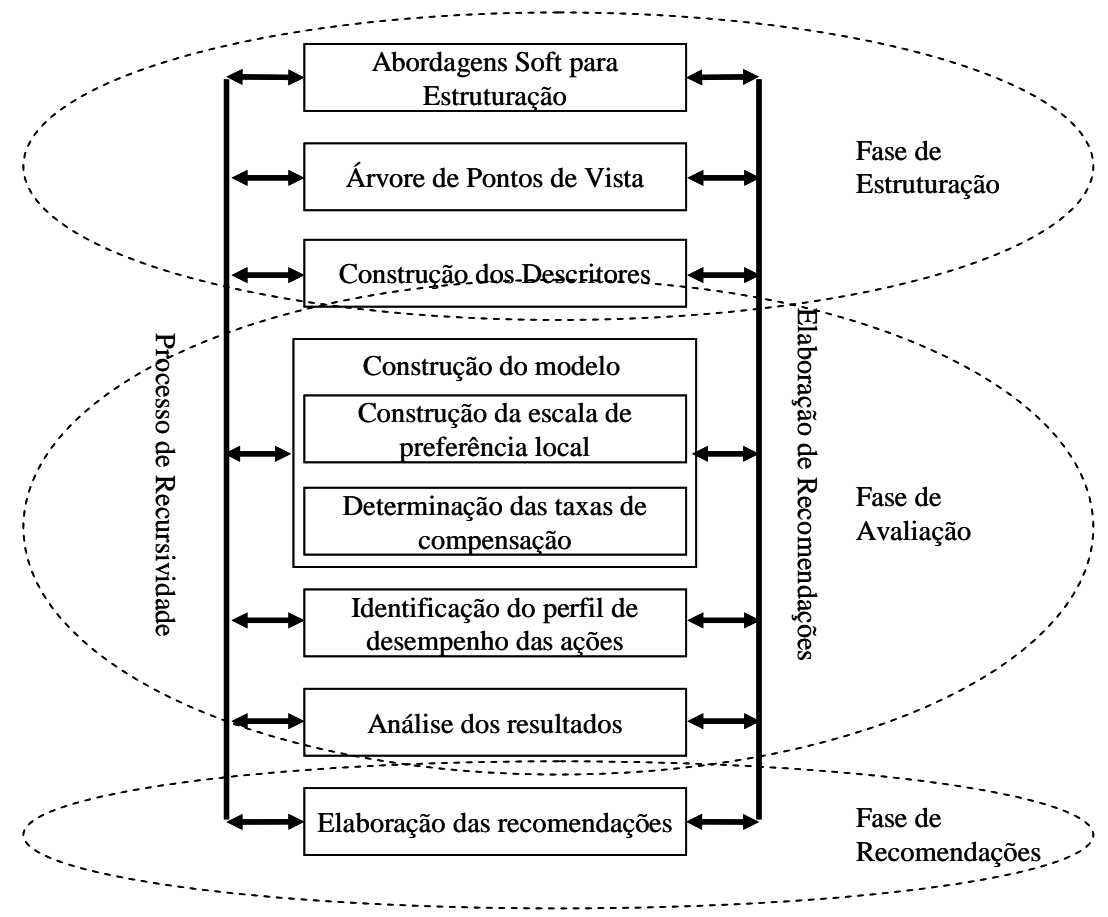

Fonte: Ensslin et al (2000).

A Avaliação consiste na incorporação de informações preferenciais dos decisores que permitam transformar as escalas ordinais em cardinais. Nesta fase são identificados os níveis de referência dos descritores e quantificados seus níveis de impactos (Função de Valor), bem como determinadas as Taxas de Substituição. A Função de Valor explicita a diferença de atratividade entre os níveis e as Taxas de Substituição a relação de compensação entre a atratividade dos intervalos de referência dos Pontos de Vista considerados (ENSSLIN et al, 2005).

Na fase de Recomendações é desenvolvido o processo de gerar ações que canalizem as discussões para o que é mais importante dentro do contexto decisório (ENSSLIN; CAMPOS, 2006). Com isto, podem ser geradas estratégias para aperfeiçoamento e aprimoramento das ações que melhor atendam aos objetivos dos decisores.

A recursividade torna o MCDA-C mais versátil e flexível, ao permitir o feedback, aos atores, em qualquer parte do processo. Presente na construção do modelo está a análise de sensibilidade, que fornece a visão de quão robusto será o modelo construído ao se alterar o impacto (conseqüência) das ações nos objetivos e/ou as Taxas de Substituição dos mesmos.

\section{Estruturação do Modelo}

Nessa fase, o contexto será representado pelos aspectos julgados pelos decisores como mais importantes. Explicitados os interesses dos atores, será fornecido um rótulo que represente o que se 
busca e identificado, organizado e mensurado ordinalmente os objetivos julgados pelos decisores como necessários e suficientes para avaliar o contexto. A estruturação visa construir o entendimento requerido para sua administração.

\subsection{Contextualização}

O Estudo de Caso foi desenvolvido na filial de uma operadora de telecomunicações localizada no Estado de Santa Catarina, situado na região sul do Brasil, com área de 95.346,18 km2 e população estimada de 5.866.568, segundo dados do IBGE (2007).

Até o início da década de 1990, o sistema de telecomunicações brasileiro era um monopólio estatal, em que as empresas estaduais pertenciam à holding Telebrás. A partir do Programa Nacional de Desestatização, a privatização tornou-se parte integrante das reformas do governo federal. Em 1995 se iniciou a privatização no ramo das telecomunicações.

Neste contexto situa-se a empresa TSC S.A, nome fictício utilizado para se referir à empresa do Estudo de Caso. A TSC possui mais de 10 milhões de linhas telefônicas, cerca de seis mil colaboradores e sua área de atuação é cerca de 33\% do território nacional. As empresas terceirizadas para poderem atuar devem ser homologadas pelo Gestor de Projetos, que emite seu parecer e o envia à matriz da TSC.

\subsection{Descrição do Problema}

O processo atual para avaliar as empresas terceirizadas que atuam nas obras sob a responsabilidade do Gestor de Projetos não evidencia os quesitos julgados relevantes e por conseqüência, a homologação das empresas é efetuada de forma intuitiva.

\subsection{Identificação dos Atores e Rótulo}

O Quadro 1 ilustra o subsistema de atores para o estudo de caso. 
Quadro 1 - Subsistema de Atores

\begin{tabular}{|c|c|c|}
\hline \multirow{7}{*}{ Stakeholders } & Decisor & Gestor de Projetos \\
\hline & \multirow{5}{*}{ Intervenientes } & Anatel \\
\hline & & Diretoria de Rede \\
\hline & & Fiscais de campo \\
\hline & & Fornecedores \\
\hline & & Gerência de Controle de Falhas \\
\hline & Facilitadores & Autores \\
\hline \multirow{3}{*}{\multicolumn{2}{|c|}{ Agidos }} & Clientes da empresa \\
\hline & & Sociedade \\
\hline & & Técnicos terceirizados \\
\hline
\end{tabular}

Fonte: Autoria própria (2008).

O Rótulo focaliza as principais preocupações do problema, e para isto, o decisor deve descrever seu problema até chegar a uma versão que considere como a mais representativa de suas preocupações. O Rótulo do estudo de caso ficou assim definido:

- Construir um modelo para avaliar o desempenho de empresas terceirizadas.

\subsection{Elementos Primários de Avaliação}

Para o levantamento dos dados foram gravadas entrevistas abertas com o decisor. Nas entrevistas, foi solicitado que o decisor falasse a respeito do problema. Suas declarações foram analisadas para identificar os Elementos Primários de Avaliação (EPAs), que são os elementos com presença obrigatória no modelo de avaliação. Os EPAs podem ser comparados aos tijolos na construção do modelo da metodologia MCDA-C, pois compõem a base do desenvolvimento do restante do processo (SANTOS, 2006).

O maior número possível de elementos devem ser identificados e novas idéias podem surgir com a combinação das pré-existentes. Foi obtido inicialmente 60 EPAs. Os 10 primeiros estão ilustrados no Quadro 2. 
Quadro 2 - Os dez primeiros EPAs identificados

\begin{tabular}{|c|l|}
\hline \multicolumn{2}{|c|}{ EPA } \\
\hline$N^{\circ}$ do EPA & \multicolumn{1}{c|}{ Descrição } \\
\hline 1 & Capacidade técnica \\
\hline 2 & Agilidade dos técnicos \\
\hline 3 & Estética das instalações \\
\hline 4 & Lançamento dos cabos \\
\hline 5 & Amarração dos cabos \\
\hline 6 & Número de testes realizados \\
\hline 7 & Identificação (etiquetagem) das instalações \\
\hline 8 & Aviso de pendências \\
\hline 9 & Gerente de Projetos na terceirizada \\
\hline 10 & Informação de ativação \\
\hline
\end{tabular}

Fonte: Autoria própria (2008).

\subsection{Conceitos}

Os Conceitos são obtidos por meio da orientação dos EPAs para as ações que sugerem. Para a construção do Conceito, deve ser identificado o objetivo subjacente ao EPA e, a seguir, solicitado ao decisor que fale a respeito do EPA, identificando: desempenho melhor possível; desempenho bom; desempenho ruim; desempenho pior possível (ainda aceitável) e a performance atual.

A seguir, o decisor identifica a intensidade com que deseja passar do intervalo pior possívelruim ao intervalo bom-melhor possível. Esta intensidade se reflete no verbo a ser utilizado na construção do conceito.

O Quadro 3 ilustra os Conceitos para os 10 primeiros EPAs.

Quadro 3 - Os dez primeiros Conceitos

\begin{tabular}{|c|l|}
\hline \multicolumn{2}{|c|}{ Conceito } \\
\hline$N^{\circ}$ do Conceito & \multicolumn{1}{c|}{ Descrição } \\
\hline 1 & Melhorar capacitação do quadro técnico ... ter retrabalho devido obras fora dos padrões \\
\hline 2 & Ter técnicos com agilidade na execução dos serviços... atrasar pagamento por entrega da obra fora do prazo \\
\hline 3 & Realizar as instalações observando a estética... ter atritos com outras áreas devido aspecto geral da instalação \\
\hline 4 & Ter em conta as previsões de futuras ampliações quando da instalação dos cabos... ter de ampliar calhas e reacomodar cabos \\
\hline 5 & Assegurar que o cabo utilizado e as atividades de seu lançamento atendam os padrões... gerar retrabalho devido cabo não adequado \\
\hline 6 & Garantir testes realizados em todos os pontos de acesso... testar por amostragem e entregar circuitos com defeito \\
\hline 7 & Fazer identificação das instalações... receber multas da Anatel \\
\hline 8 & Enviar aviso de pendências... ocasionar deslocamentos desnecessários do auditor \\
\hline 9 & Possuir Gerente de Projetos... ter atritos com terceirizada pelo recebimento de informações incorretas \\
\hline 10 & Enviar e-mail comunicando ativação... atrasar liberação para a área comercial devido à não informação da conclusão dos serviços \\
\hline
\end{tabular}
Fonte: Autoria própria (2008).

\section{6 Áreas de Preocupação}

Os Conceitos que possuem preocupações comum, segundo o decisor, podem ser agrupados 
em Áreas de Preocupação, e com isto se ter uma visão macroscópica do modelo de avaliação (SILVEIRA, 2007). Os nomes dados às áreas refletem a preocupação principal do decisor ao expressar os conceitos pertencentes ao agrupamento.

A Figura 2 representa as Áreas de Preocupação do Estudo de Caso e os respectivos conceitos.

Figura 2 - Áreas de Preocupação

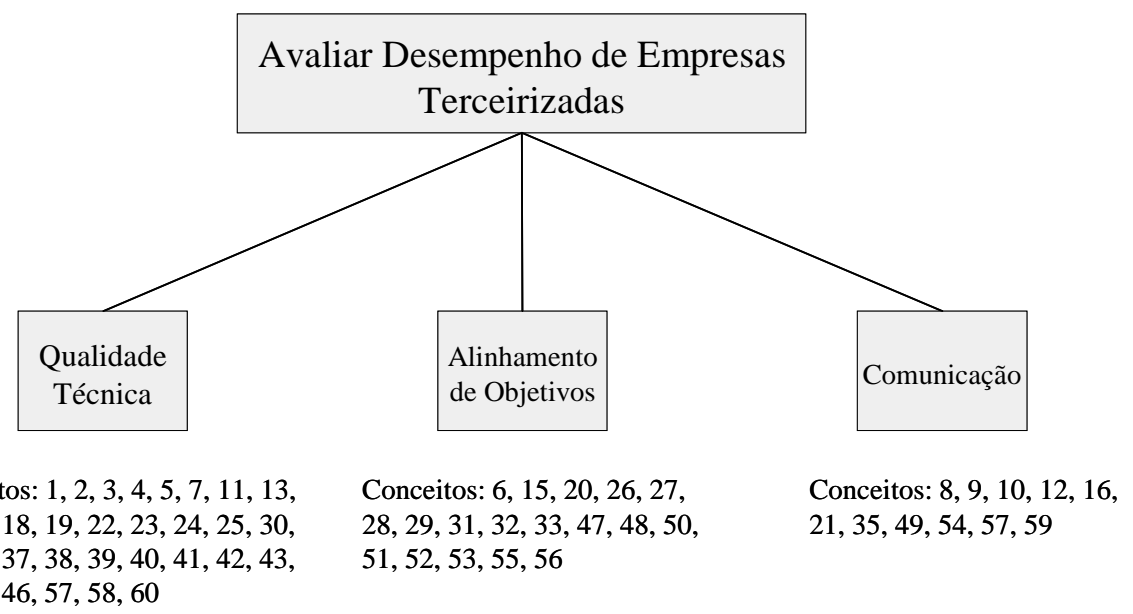

Fonte: Autoria própria (2008).

\subsection{Mapas Meios-Fins}

Um Mapa Meios-Fins é uma forma de representar o problema do decisor por meio da explicitação da hierarquia entre os conceitos com as ligações de influência entre os meios e os fins (ENSSLIN et al, 2001). Sua construção se obtém perguntando ao decisor, para cada conceito, as seguintes questões: “Como posso obter o conceito fim?” e "Por que o conceito meio é importante?”. Os Mapas Meios-Fins irão refletir o que deve constar no modelo de avaliação de desempenho. O conjunto dos Mapas Meios-Fins forma o Mapa Global, que é dividido em mapas menores formando os Clusters. Os Clusters são formados ao serem agrupados os ramos cuja argumentação reflete um mesmo interesse do decisor. O nome de cada Cluster é dado em função do foco de interesse do decisor expresso pelos ramos.

A Figura 3 ilustra os Mapas Meios-Fins para os Clusters Qualificação Profissional e Testes. Os conceitos não numerados são os que emergiram no momento da construção do Mapa. 


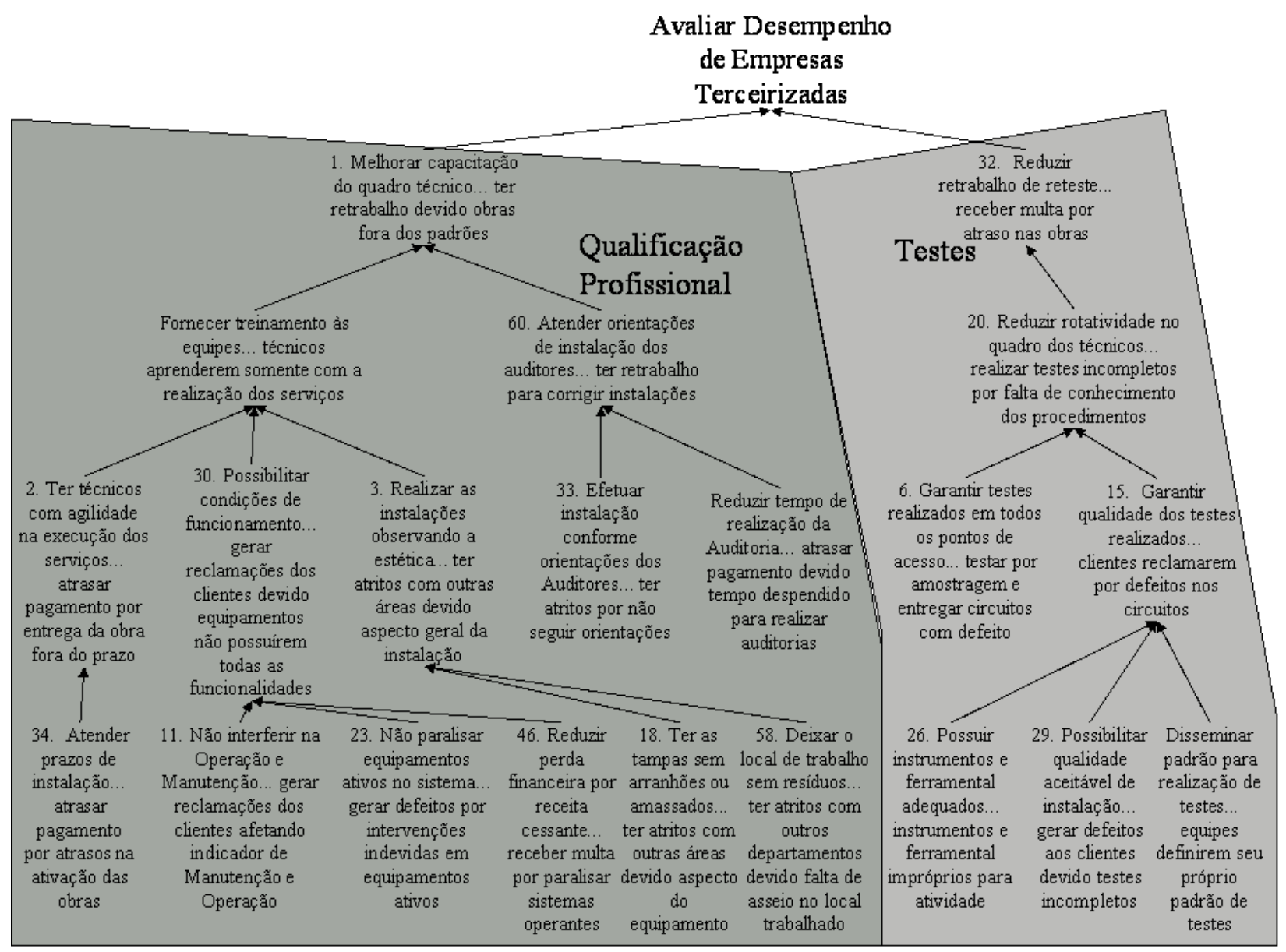

Fonte: Autoria própria (2008).

\section{8 Árvore de Pontos de Vista Fundamentais (PVFs)}

Construído o Mapa Global, pode-se fazer seu enquadramento para determinar quais são os Clusters (conjunto de conceitos inter-relacionados) que representam os objetivos ou os Pontos de Vista Fundamentais. Este processo permite migrar do Mapa de Relações Meios-Fins para a estrutura explicativa da Árvore de Valor ou modelo multicritério, com o entendimento do que é, e quais propriedades do contexto são utilizadas para medir seu desempenho.

Os Clusters do Mapa Global constituem uma Família de Candidatos a Pontos de Vista Fundamentais. Cada candidato da Família, para se tornar um PVF, deve ser essencial, controlável, completo, mensurável, operacional, isolável, não-redundante, conciso e compreensível (ENSSLIN et al, 2001).

Identificados os PVFs, pode-se construir a Estrutura Arborescente dos PVFs, conforme Figura 4. No Estudo de Caso desenvolvido, foi adotado o mesmo nome dos Clusters para os PVFs, visando facilitar a compreensão ao decisor. 


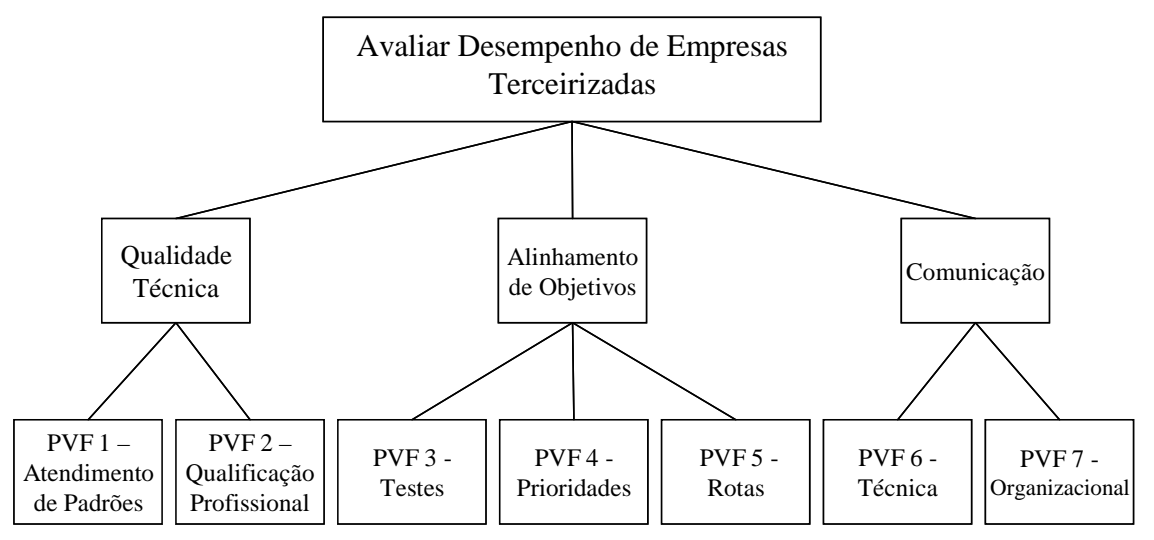

Fonte: Autoria própria (2008).

\subsection{Estrutura Hierárquica de Valor e Descritores}

Para mensurar os PVFs retorna-se ao Mapa Meios-Fins e repete-se o processo de identificação agora dos subclusters dentro do cluster em estudo. Cada subclusters ao ser transferido para a estrutura explicativa da Árvore de Valor recebe o nome de PVE (Ponto de Vista Elementar). Este processo é repetido até que se alcance uma propriedade mensurável do contexto. Identificado o PVE mensurável constrói-se a escala ordinal que o irá mensurar. A esta escala denomina-se descritor (PETRI, 2000).

Para cada Descritor foi construído uma Escala Ordinal contendo os diferentes níveis de impacto e a indicação do sentido de preferência que conduz ao objetivo. Para que o descritor possa ser usado como elemento de comparação de desempenho, devem ser estabelecidos, pelo decisor, os Níveis de Referência ou Âncoras denominados de Nível Bom, que representa o desempenho acima do qual o decisor julga excelente, e de Nível Neutro que é a fronteira abaixo da qual o desempenho é comprometedor. Entre os dois pontos o desempenho é competitivo.

A Figura 5 ilustra a Estrutura Hierárquica de Valor, os descritores e as escalas ordinais para o PVF Qualificação Profissional. Ao todo foram construídos 54 descritores. 
Figura 5 - Estrutura Hierárquica de Valor, Descritores e Escalas Ordinais do PVF Qualificação Profissional

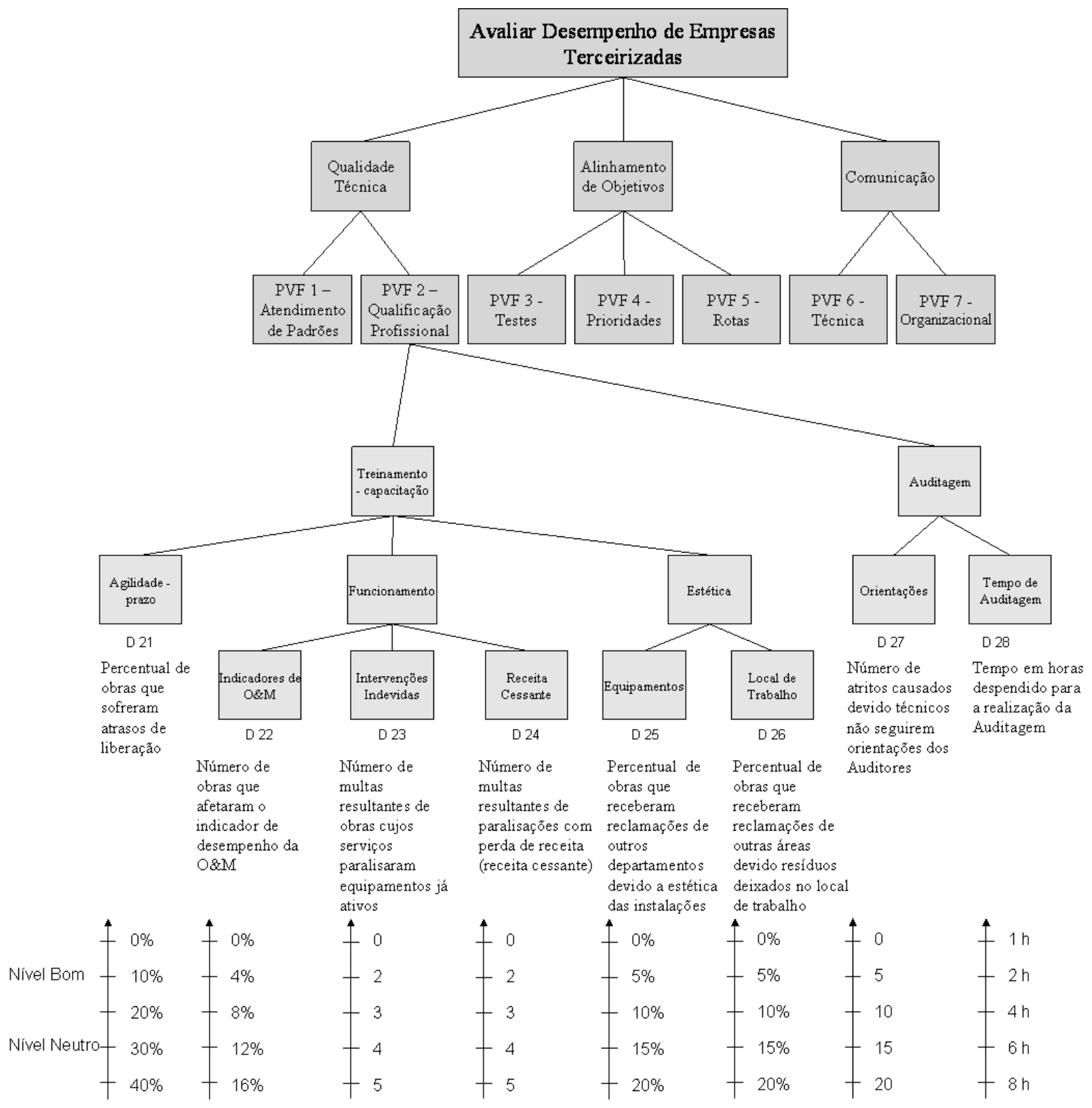

Fonte: Autoria própria (2008).

\section{Avaliação}

Na fase de Avaliação são determinadas as Funções de Valor, as Taxas de Substituição, a Agregação Aditiva do modelo, traçado o perfil de impacto das ações potenciais e analisado a Sensibilidade dos resultados obtidos.

\subsection{Funções de Valor}

A Função de Valor quantifica a intensidade de preferência, ou diferença de atratividade, 
entre os diferentes níveis de impacto das ações potenciais. O método utilizado foi o MACBETH (Measuring Attractiveness by a Categorical Based Evaluation Technique) (BANA E COSTA et al, 2003), que se valendo de escalas semânticas propõe a função de valor que atenda a todos os juízos de valor do decisor.

Sua realização se dá com o questionamento ao decisor sobre a diferença de atratividade de ações potenciais para cada intervalo do descritor. As informações são compiladas na Matriz de Julgamentos, em que o número 0 equivale à atratividade nula, o número 1 à muito fraca, o 2 à fraca, o 3 à moderada e assim sucessivamente até o número 6 que representa a extrema. O Quadro 4 exibe a Matriz de Julgamento para o Descritor Cláusulas Contratuais.

Quadro 4 - Matriz de Julgamento para Descritor Cláusulas Contratuais

\begin{tabular}{|c|c|c|c|c|c|c|c|}
\hline \multirow{3}{*}{ Nivel Bom } & \multirow{3}{*}{$+\begin{array}{l}100 \% \\
95 \%\end{array}$} & & $100 \%$ & $95 \%$ & $90 \%$ & $85 \%$ & $80 \%$ \\
\hline & & $100 \%$ & $X$ & 2 & 3 & 4 & 5 \\
\hline & & $95 \%$ & & $\mathrm{X}$ & 2 & 3 & 4 \\
\hline \multirow{3}{*}{ Nivel Neutro } & $90 \%$ & $90 \%$ & & & $\mathrm{X}$ & 3 & 4 \\
\hline & $85 \%$ & $85 \%$ & & & & $\mathrm{X}$ & 3 \\
\hline & $-80 \%$ & $80 \%$ & & & & & $\mathrm{X}$ \\
\hline
\end{tabular}

Fonte: Autoria própria (2008).

O Quadro 5 demonstra as escalas base e ancoradas fornecidas pelo software Macbeth para o Descritor Cláusulas Contratuais.

Quadro 5 - Escalas fornecidas pelo Macbeth para o Descrit
\begin{tabular}{|r|r|r|r|}
\hline & $\begin{array}{r}\text { Escala } \\
\text { actual }\end{array}$ & $\begin{array}{c}\text { MACBETH } \\
\text { ancorada }\end{array}$ & $\begin{array}{c}\text { MACBETH } \\
\text { de base }\end{array}$ \\
$\qquad$ niv1 & $\mathbf{1 0 0}$ & $\mathbf{1 4 0 . 0 0}$ & $\mathbf{1 0 . 0 0}$ \\
\hline niv2 & 80 & $\mathbf{1 0 0 . 0 0}$ & $\mathbf{8 . 0 0}$ \\
\hline niv3 & 60 & 60.00 & 6.00 \\
\hline niv4 & 30 & 0.00 & 3.00 \\
\hline riv5 & 0 & -60.00 & $\mathbf{0 . 0 0}$ \\
\hline
\end{tabular}

Fonte: Bana e Costa et al (2005).

A partir da Escala Ancorada traça-se o gráfico que representa a Função de Valor para o Descritor, ilustrada no Gráfico 1 para o mesmo descritor. 
Gráfico 1 - Função de Valor para o Descritor Cláusulas Contratuais

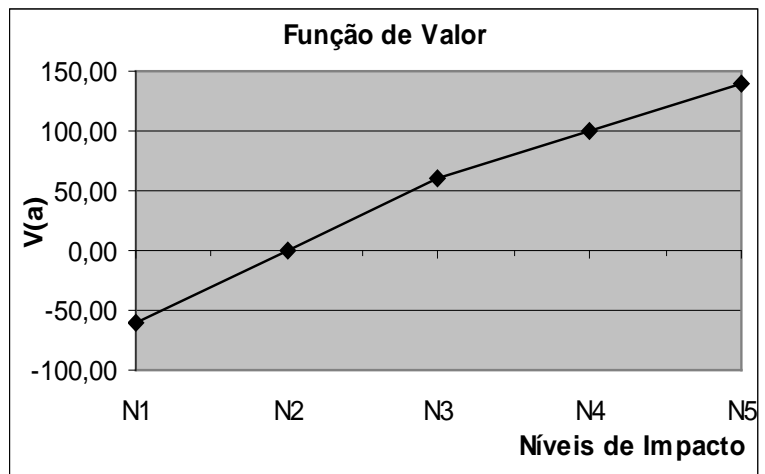

Fonte: Autoria própria (2008).

A Figura 6 apresenta o conjunto de Escalas Ancoradas para os descritores do PVF Qualificação Profissional.

Figura 6 - Escalas Ancoradas para os Descritores do PVF Qualificação Profissional

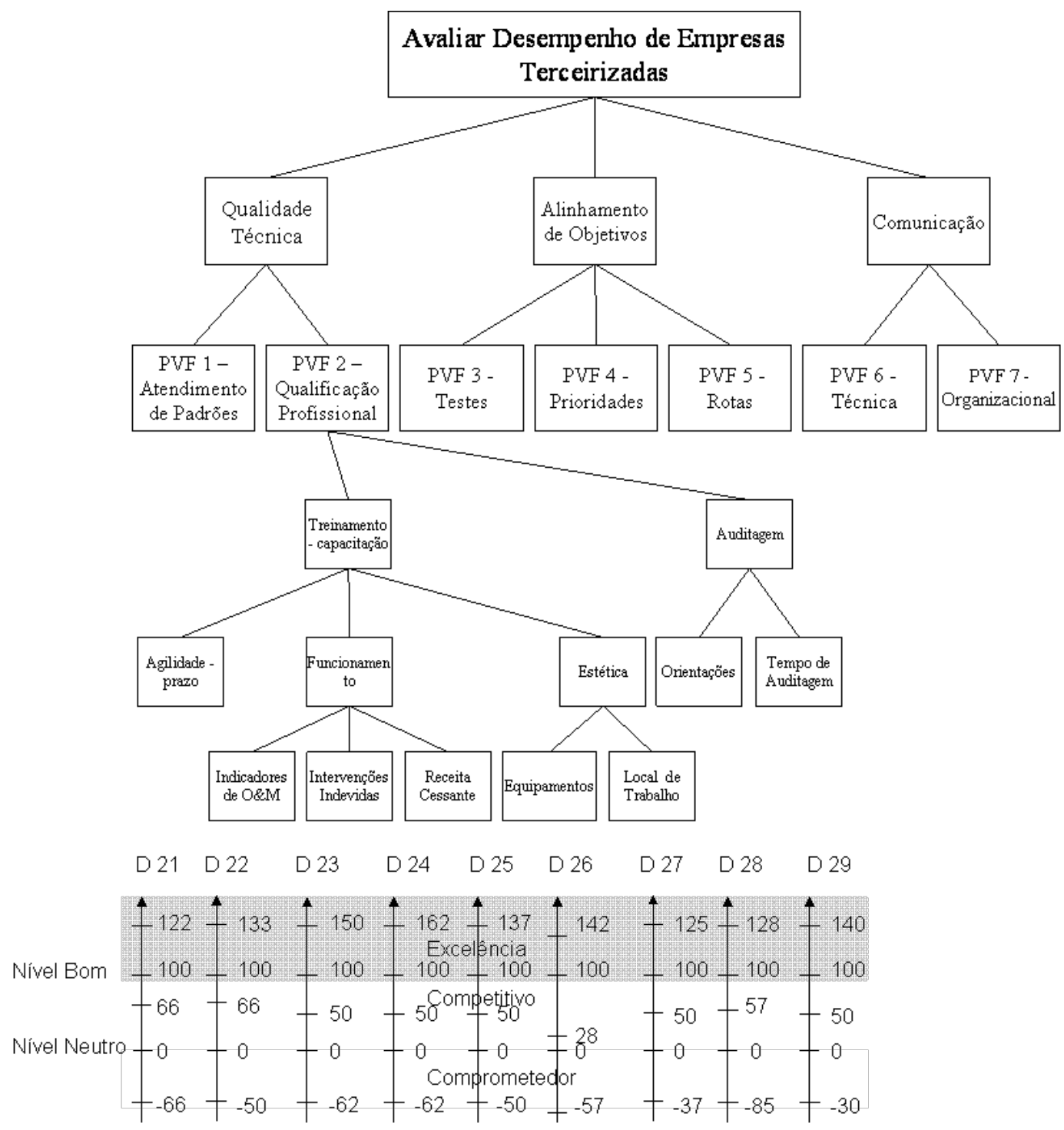

Fonte: Autoria própria (2008). 


\subsection{Taxas de Substituição}

A etapa seguinte na construção do modelo consiste em agregar as avaliações de ações locais sobre cada critério em uma avaliação global que melhor permita a comparação das diferentes ações.

A agregação é realizada por meio das taxas de Substituição (SILVEIRA, 2007). O método utilizado foi o de Comparação Par-a-Par do Macbeth. Para isto, atribui-se o impacto de uma ação potencial que produza o Nível Bom a um critério e Neutro para os demais. A seguir atribui-se o impacto de uma segunda ação potencial que produza o inverso e pergunta-se ao decisor qual das duas ações potenciais prefere. Na seqüência é solicitado ao decisor que julgue semanticamente a diferença de atratividade quando se troca de uma ação para outra. As categorias semânticas utilizadas são as mesmas empregadas para obter as Funções de Valor. Os valores atribuídos são inseridos no Macbeth, que fornece as Taxas de Substituição.

A Figura 7 ilustra as Taxas de Substituição do modelo construído.

Figura 7 - Taxas de Substituição

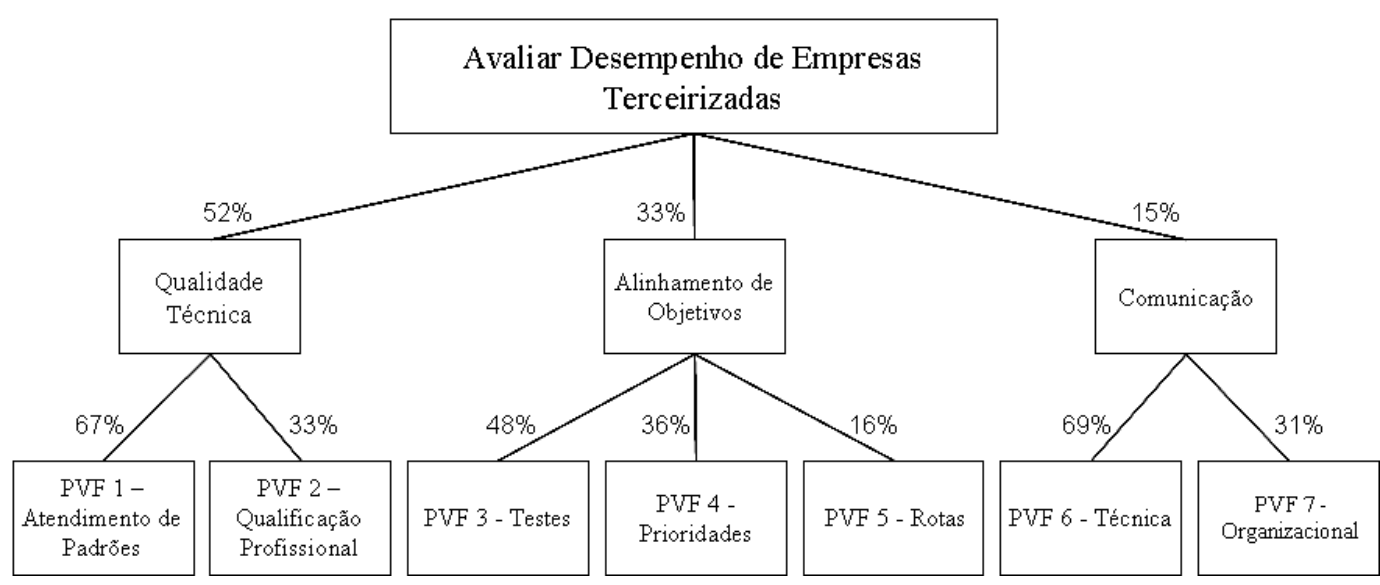

Fonte: Autoria própria (2008).

\subsection{Avaliação Global e Perfil de Impacto da Situação Atual}

Para que se possa avaliar globalmente o impacto de uma ação é necessário utilizar uma forma de agregar as avaliações locais da ação. O que se faz é uma soma ponderada com a pontuação obtida pela ação em cada critério multiplicada pelo peso correspondente ao critério, por meio da fórmula [1].

$$
V_{P V F_{k}}(a)=\sum_{i=1}^{n_{k}} w_{i, k} \bullet v_{i, k}(a)
$$

Em que: 
valor global da ação a do PVFk, para $\mathrm{k}=1, \ldots \mathrm{m}$;

vi,k(a): valor parcial da ação a no critério i, i $=1, \ldots \mathrm{n}$, do PVFk, para $\mathrm{k}=1, \ldots \mathrm{m}$;

a: nível de impacto da ação a;

wi,k : taxas de substituição do critério i, i $=1, \ldots \mathrm{n}$, do PVFk, para $\mathrm{k}=1, \ldots \mathrm{m}$;

nk: número de critérios do PVFk, para $\mathrm{k}=1, \ldots \mathrm{m}$;

m: número de PVFs do modelo.

Pode-se agora realizar a avaliação de desempenho de uma empresa terceirizada. Para tal, para cada descritor, o decisor determina o nível de impacto da ação a em cada critério i, i=1,... n; gj(a).

Com esta informação, determina a pontuação parcial da ação a em cada critério i, i=1,... n; vi(gj(a)) e com a equação global de avaliação fornecida pela fórmula [1] calcula o valor da performance da terceirizada. A Figura 8 ilustra a avaliação dos valores parciais e, no alto à direita, a global para uma empresa real selecionada pelo decisor.

O traçado do Perfil de Impacto permite identificar onde estão os pontos fortes da empresa avaliada e em quais PVFs residem as principais oportunidades de melhoria. Isto possibilita realizar o feedback à empresa de quais são os aspectos que devem apresentar melhora de desempenho.

Figura 8 - Perfil de Impacto da Situação Atual nos PVFs

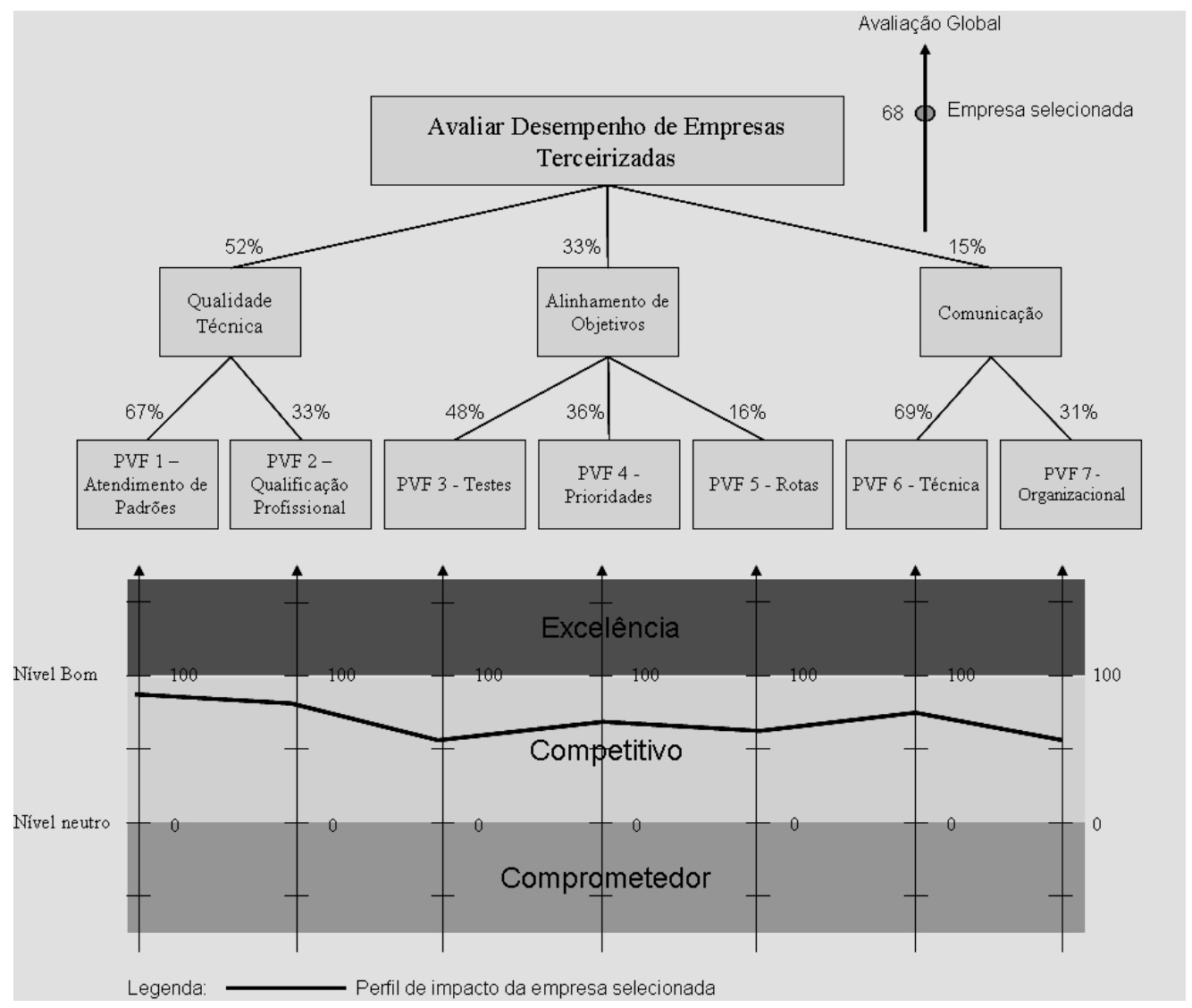

Fonte: Autoria própria (2008). 


\subsection{Análise de Sensibilidade}

O objetivo de realizar uma Análise de Sensibilidade no modelo construído é a de determinar o grau de estabilidade da avaliação quando de mudanças ou no impacto das ações nos critérios e/ou quando de variação das taxas de Substituição.

Para realizar a análise de sensibilidade foi utilizado o software Hiview (BARCLAY, 2006). O Gráfico 2 ilustra a sensibilidade da Taxa de Substituição para o PVF Atendimento de Padrões ao se aplicar as Estratégias de Ações Potenciais à empresa terceirizada real selecionada pelo decisor. Ao analisar o gráfico, percebe-se que a Taxa de Substituição do PVF pode sofrer uma redução de até aproximadamente $56 \%$ e ainda assim a ordenação das alternativas é mantida. Essa foi a menor variação permitida entre os PVFs. Com isto, o modelo construído se revela robusto para avaliar e ordenar as empresas terceirizadas consideradas. Caso forem adicionadas novas empresas para serem analisadas, a sensibilidade deve ser mais uma vez verificada.

Gráfico 2 - Sensibilidade para PVF Atendimento de Padrões

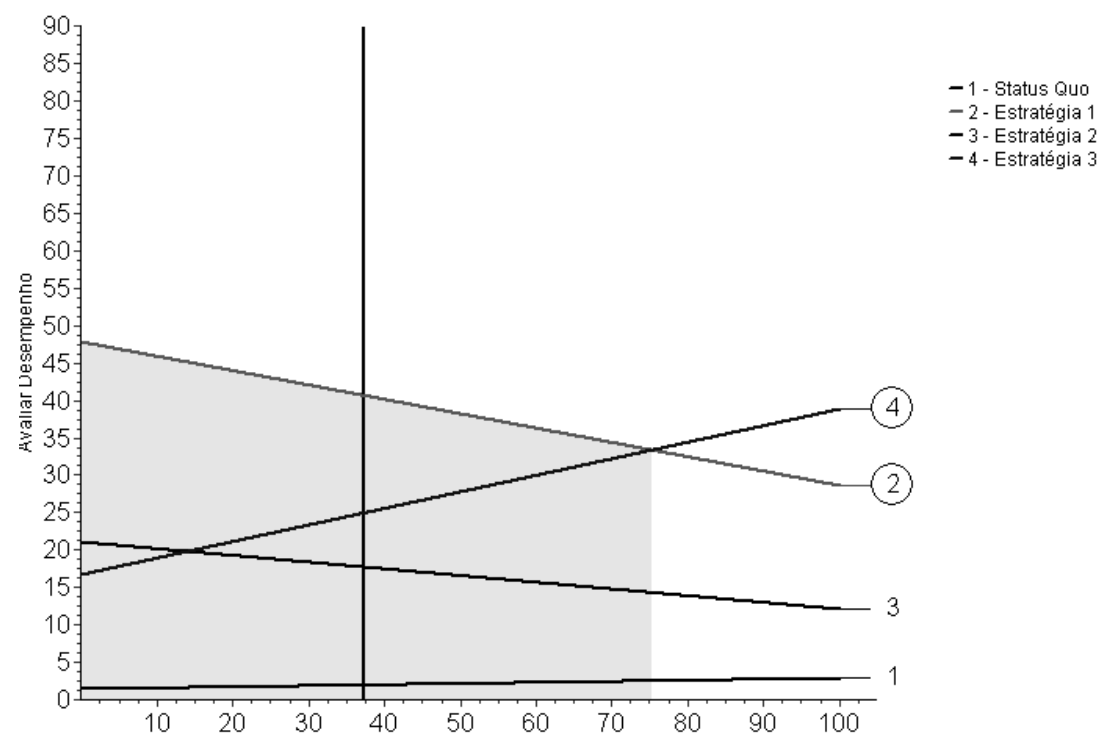

Fonte: Autoria própria (2008).

\section{Recomendações}

Construído o modelo multicritério procede-se a elaboração de Recomendações de Ações Potenciais, com o objetivo de caracterizar a forma como aumentou o entendimento sobre o problema analisado pelo Estudo de Caso (SILVEIRA, 2007).

A identificação das ações foi efetuada pelo facilitador e pelo decisor. As ações identificadas foram agrupadas segundo perspectivas afins. 
A seguir, descrevem-se algumas das ações potenciais geradas, segundo as respectivas perspectivas.

\section{a) Capacitação e Treinamento:}

- $\quad$ Auditores atuarem na orientação aos técnicos, dirimindo as dúvidas quanto aos detalhes das instalações, ficando disponíveis para atendimento por telefone, e-mail ou indo até o local para uma orientação presencial;

- $\quad$ Estabelecer parcerias com centros de treinamento para o aperfeiçoamento dos colaboradores;

- $\quad$ Ter explicitado quais são os critérios requeridos a cada função dos colaboradores da contratante e da terceirizada, envolvidos com as obras.

\section{b) Comunicação:}

- $\quad$ Apresentação dos critérios de avaliação das terceirizadas, aos envolvidos, em reunião antes do início das obras;

- $\quad$ Comunicação técnico-gestor possa ser on-line, via ambiente web proposto;

- Divulgar na reunião inicial a última avaliação da empresa, para empresas que já trabalharam em outros projetos;

- $\quad$ Em situações que tenham originado conflitos ou paralisações, enviar para o e-mail do técnico e para o gerente de projeto da terceirizada, com aviso de recebimento, formalização da ocorrência da situação problema.

\section{c) Controle de Qualidade:}

- Criar Círculos de Qualidade para examinar os processos e sua adequabilidade, eficiência, eficácia, efetividade, que contem com a participação de representantes de diversas áreas da empresa, com representantes das terceirizadas e de fornecedores;

- $\quad$ Gerar relatórios que analisem o índice de reclamações originadas pelos clientes;

- Gerar relatórios que indiquem a quantia de falhas apontadas pelo sistema de gerenciamento.

\section{d) Facilidade Computacional:}

- $\quad$ Adequar gestão dos projetos alimentando e atualizando o status quo do andamento da obra por parte da contratada em um ambiente web, compartilhado entre terceirizada e contratante;

- $\quad$ Cadastro das informações técnicas on-line via web, pela própria terceirizada;

- $\quad$ Criar no ambiente web do projeto, espaço privativo para anotações da contratante a 
partir da demanda por retrabalho, reclamações, não conformidade, pontos fracos e pontos fortes da terceirizada, parecer do gestor, de forma que o gerente de projetos possa comparar em tempo real o andamento dos contratos e a qualidade da contratada, gerando documento para avaliação das terceirizadas em futuros contratos.

\section{e) Gestão do Projeto:}

- Adequar os contratos para que a parcela de pagamento seja uniformemente distribuída pela quantia de eventos de pagamentos, para que a última parcela, referente à retirada total de pendências, seja financeiramente importante.

- $\quad$ Auditores alimentarem o sistema web com propostas, por parte dos técnicos, de adequações no sistema de avaliação, em potenciais pontos considerados punitivos.

- Coerência quanto ao atendimento dos prazos de instalação e a integridade física/saúde dos colaboradores.

\section{f) Infra-estrutura:}

- $\quad$ Desenvolver uma bancada de teste que acople o bloco a ser testado possua vários “modems” internos e que desenvolva a rotina de teste automaticamente em um notebook. Os resultados dos testes possam ser anexados no ambiente web da obra correspondente;

- $\quad$ Testar diferentes modelos de fixadores de cabos para agilizar amarração e fixação dos mesmos com qualidade equivalente ou superior ao modelo atual;

- Utilizar calhas com a capacidade correta de cabos; engates rápidos para cabos de energia e aterramento.

A partir da combinação entre os agrupamentos foram propostas Estratégias de Ações Potenciais, segundo as Perspectivas que se deseja focar.

Obtidas as propostas de Estratégias de Ações Potenciais, chega-se ao final da construção do modelo de avaliação de desempenho. No entanto, há que se lembrar da recursividade do processo e da constante alteração do contexto do ambiente decisional, resultando na necessidade da periódica revisão do modelo para a nova realidade.

\section{Considerações Finais}

A postura inicialmente reticente do Gestor de Projetos deu lugar ao longo do processo de construção do modelo a um entendimento cada vez maior da própria problemática, servindo de subsídio ao processo de gerar as ações potenciais de aperfeiçoamento, sendo esse um dos pontos fortes da utilização da metodologia MCDA-C. O modelo construído foi legitimado pelo decisor em cada etapa de sua construção, e com sua utilização, o decisor e a operadora de telecomunicações passaram a contar com um instrumento que oportuniza a melhoria contínua na gestão do 
desempenho das empresas terceirizadas, aberto a ações criativas e inovadoras para a melhora do desempenho.

A MCDA-C possibilitou ao decisor estruturar o problema pela identificação dos atores envolvidos, elicitação dos EPAs, construção dos conceitos e identificação das Áreas de Preocupação. Por meio da hierarquização dos conceitos nos Mapas Meios-Fins foi possível se chegar aos PVFs, e a partir daí, à construção da Estrutura Hierárquica de Valor e dos Descritores. Com os descritores construídos, o decisor teve condições de medir o desempenho de uma empresa terceirizada que lhe presta serviços e identificar quais são os pontos fortes e onde residem as oportunidades de melhoria da empresa avaliada.

A transferência de tecnologia proporcionada pela participação, aprendizagem e entendimento crescente do decisor na construção do modelo deverão orientar o desenvolvimento e o uso do mesmo em suas múltiplas possibilidades, referendando a prática construtivista da MCDA-C e orientando futuros estudos.

\begin{abstract}
The brazilian acelerated process of growth in the telecommunications sector initiated by the privatization of the Telebrás system, unchained the adoption of the Outsourcing in the projects of expansion and implantation of the data and voice equipments by the companies who operates the system. However, the scarcity or the absence of models of performance evaluation of the outsourced companies, that evidence important criteria for the decisores, favors the situation where the decisions of to sign the contracts with the outsourcers predominantly are based on intuitive criteria, favoring the possibility of the occurrence of innumerable problems such as rework, incidental costs and, over all, wearing in the image of the telecommunications companies for its customers. The present article uses the Multicriteria Decision Aid - Constructivist (MCDA-C) approach to develop a model of performance evaluation of the outsourced companies who works in the telecommunications sector.
\end{abstract}

Key-words: performance evaluation, organizational management, project management, multicriteria decision aid.

\title{
Referências
}

BANA E COSTA, C. A. Três convicções fundamentais na prática do apoio à decisão. Pesquisa Operacional, vol. 13, n. 1, jun. 1993.

BANA E COSTA, C. A.; DE CORTE, J. M.; VANSNICK, J. C. Macbeth. 2003. Disponível em: <http://www.lse.ac.uk/collections/operationalresearch/pdf/ macbeth lse\%20working\%20paper\%200356\%2030set.pdf>. Acesso em: 18 nov. 2006.

BANA E COSTA, C. A.; DE CORTE, J. M.; VANSNICK, J. C. Software M-Macbeth. Versão demo 1.1 não registrada. Versão 2005. 2005. Disponível em: <http://www.m-macbeth.com>. Acesso em: 17 out. 2006.

BARCLAY, S. Software Hiview3. Trial version - not licensed for commercial use. Versão 3.1.0.4. 2006 Disponível em: <http://www.catalyze.co.uk/products/hiview>. Acesso em: 18 dez. 2006.

BERGAMASCHI, S. Modelos de gestão da terceirização de tecnologia da Informação: um estudo exploratório. 2004. 197 f. Tese (Doutorado em Administração) - Programa de Pós-Graduação em Administração, Universidade de São Paulo, São Paulo.

ENSSLIN, L.; DUTRA, A.; ENSSLIN, S. R. MCDA: a construtivist approach to the management of human resources at a governmental agency. International Transactions in Operational Research, 7, p. 79-100. 2000. 
ENSSLIN, S.; ENSSLIN, L.; DUTRA, A.; IGARASHI, D. C. C. Visão hard ou visão soft da pesquisa operacional? Reflexões sobre posturas e procedimentos. In: XII SIMPEP, Anais... Bauru: SIMPEP, 2005.

EnSSlin, L.; MONTIBELler, G.; NOROnHA, S. M. Apoio à decisão: metodologias para estruturação de problemas e avaliação multicritério de alternativas. Florianópolis: Insular, 2001.

ENSSLIN, L.; CAMPOS, M. L. A prática do aprendizado organizacional. Revista Gestão Industrial, vol. 2, n. 1, p. 59-69. 2006. Disponível em: <http://www.pg.cefetpr.br/ppgep/revista/revista2006/pdf/RGIv02n01a6.pdf>. Acesso em: 31 mar. 2007.

ENSSLIN, L.; VIANNA, W. B. O Design na Pesquisa Quali-quantitativa em Engenharia de Produção - Questões a considerar. Revista Gestão Industrial, Ponta Grossa, vol. 3, n.3, p. 172-185. 2007.

IBGE. Instituto Brasileiro de Geografia e Estatística. 2007. Disponível em <http://www.ibge.gov.br/estadosat/perfil. php?sigla=sc>. Acesso em: 07 mai. 2007.

PETRI, S. M. Construção de um modelo de avaliação de desempenho em uma prestadora de serviços contábeis para identificar oportunidades de melhorias utilizando a metodologia MCDA. 2000. 251 f. Dissertação (Mestrado em Engenharia de Produção) - Programa de Pós-Graduação em Engenharia de Produção, Universidade Federal de Santa Catarina, Florianópolis.

RAMOS, L. G. T. A gestão dos processos de terceirização e sua implementação na indústria automobilística. 2002. 61 f. Monografia (Especialização em Gerência de Produção e Tecnologia) - Programa de MBA em Economia, Ciências Contábeis, Administração e Secretariado, Universidade de Taubaté, Taubaté.

ROY, B., VANDERPOOTEN, D. The European School of MCDA: Emergence, Basic Features and Current Works. Journal of Multi-Criteria Decision Analysis, vol. 5, pp. 22-38. 1996.

SANTOS, J. L. Avaliação de um software utilizando a metodologia MCDA-C: um estudo de caso. $2006.334 \mathrm{f}$. Dissertação (Mestrado em Engenharia de Produção) - Programa de Pós-Graduação em Engenharia de Produção, Universidade Federal de Santa Catarina, Florianópolis.

SILVEIRA, C. F. Avaliação de desempenho com foco no marketing de relacionamento: um estudo de caso. 2007. 170 f. Dissertação (Mestrado em Engenharia de Produção) - Programa de Pós-Graduação em Engenharia de Produção, Universidade Federal de Santa Catarina, Florianópolis.

\section{DADOS DOS AUTORES}

\section{Nome completo: Edilson Giffhorn}

Filiação institucional: Universidade Federal de Santa Catarina

Departamento: Engenharia de Produção e Sistemas

Função ou cargo ocupado: Doutorando em Engenharia de Produção

Endereço completo para correspondência: Rod. Amaro A. Vieira, 655, apt. 106-E, Itacorubi, Florianópolis-SC, CEP. 88.034-101.

Telefones para contato: 48 3234-9435

e-mail: edilson.giffhorn@gmail.com

\section{Nome completo: Leonardo Ensslin}

Filiação institucional: Universidade Federal de Santa Catarina

Departamento: Engenharia de Produção e Sistemas

Função ou cargo ocupado: Professor Titular 
Endereço completo para correspondência: Universidade Federal de Santa Catarina - Campus Universitário, Trindade, Florianópolis, Santa Catarina, CEP. 88.040-900; CP. 476.

Telefones para contato: 48 3721-7022

e-mail:ensslin@deps.ufsc.br

\section{Nome completo: Sandra Rolim Ensslin}

Filiação institucional: Universidade Federal de Santa Catarina

Departamento: Ciências Contábeis

Função ou cargo ocupado: Professora Adjunta

Endereço completo para correspondência: Universidade Federal de Santa Catarina - Campus Universitário, Trindade, Florianópolis, Santa Catarina, CEP. 88.040-900; CP. 476.

Telefones para contato:

e-mail:sensslin@gmail.com

Nome completo: William Barbosa Vianna

Filiação institucional: Universidade Federal de Santa Catarina

Departamento: Engenharia de Produção e Sistemas

Função ou cargo ocupado: Doutorando em Engenharia de Produção

Endereço completo para correspondência: Rua Cônego Bernardo, 100, apt. 202, Trindade, Florianópolis, Santa Catarina, CEP. 88.036-570

Telefones para contato: 48 8421-0241

e-mail:wpwilliam@hotmail.com 